gone and a new system of leadership and decision-making is necessary.

Many psychiatrists know that to work in a multidisciplinary team setting does not require the relinquishing of their responsibility and authority. Quite the contrary. In no other situation is skilled leadership more necessary. The intelligent sharing of relevant information and skills in such a setting can be very much to the patient's advantage, leading as it does to action which is carried through with greater insight and motivation just because it was discussed and shared beforehand.

I agree that the NHS is crying out for clear medical leadership. But we must ensure that we take our non-medical colleagues with us in a way that recognises their own ability and acknowledges that, from time to time, this may even better our own.

The Ross Clinic,

J K W MORRICE

The Ross
Aberdeen ${ }^{1}$ Morrice, J K W, British four nal of Medical Psychology,
1972, 45, 327.

SIR,-Your leading article on this subject (19 March, p 736) seems, if one reads it aright, to imply a desire on the part of those not working in the mental health services to see a return of medical superintendency in such hospitals. It would be very interesting to know if a similar desire for an authoritarian head of department exists in other types of medical practice. It would be even more interesting to know if the measures which you advocate are acceptable to those of us working in the psychiatric field.

A much more balanced and, dare I say, experienced view of the position was set out recently in your own columns by $\mathrm{Dr} \mathrm{J} \mathrm{J}$ Cockburn (16 October, 1976, p 929). A rereading of this article might be a salutary counter to your own recent expression of view. What is really very much more relevant is that one has to live in the world as it is and accept in this instance, for example, that workers in the Health Service are not subservient to the medical diktat and that a return to the status of the medical superintendent (who was, I am sure you will recall, "the medical officer" as defined by the Lunacy Act of 1890) would be opposed on all sides, not least probably by the medical staff in psychiatric hospitals themselves.

B W ORCHARD Chairman, Norwich Health District
Psychiatric Division

Hellesdon Hospital,

Norwich

\section{Mobility for the disabled}

SIR,-Professor Cairns Aitken's letter (19 February, p 507) emphasises the lack of precision in one of the criteria for the mobility allowance-that the patient must be "virtually unable to walk." This is a subjective judgment in many cases; in others the ability to walk varies with the seasons (the winter bronchitic), the external environment (the arthritic has difficulty in wind, rain, and icy conditions and on flagstones and slopes), and the state of the disease (which may be fluctuating as in multiple sclerosis). In addition, an increasingly elderly population is likely to suffer from more than one disability, with cumulative effects on mobility.
In a recent survey of outpatients with rheumatoid arthritis or osteoarthrosis in Leeds, sponsored by the Arthritis and Rheumatism Council, which we hope to present to a scientific meeting of rheumatologists shortly, we found the following facts which bear directly on the mobility of this group, who form over $20 \%$ physically handicapped of this country. ${ }^{1}$ (1) One-third of the subjects (and over half the over-75-year-olds) could not get farther than 10 yards on foot. Half could not walk 100 yards. (2) Many bus-stops and most shops are more than 100 yards away. (3) Over $40 \%$ subjects had a second diagnosis impairing mobility. (4) Almost half the handicapped rarely or never used public transport and only one in three of these had access to a car $(16 \%$ of the total). (5) The average income of these households was much below the national average.

Current provision fails to secure adequate mobility to prevent the social isolation of most of this section of the population. In many cases in which the subject is in employment the mobility allowance nowhere near covers the cost of getting to work.

\section{A ChamberLain} JEAN BUCHANAN

Rheumatology and Rehabilitation

Research Unit,

University of Leed

' Harris, A, Handicap and Impairment in Great Britain,

Part 1. London, HMSO, 1971.

\section{Staffing in hospital laboratories}

SIR,-I would like to lend my full support to the sentiments expressed in the letter from Professor W A J Crane and others (12 February, p 441). Having read the Institute of Medical Laboratory Sciences policy statement on future staffing in the medical laboratory service (November 1976) I am amazed by some of the statements contained therein which can do nothing but harm to our current laboratory services requirement vis-à-vis patient management. There can be no question that the manager of a laboratory department must be medically qualified. I cannot accept that senior members of the laboratory technician staff can decide on the priorities of medical tests required, based on clinicians' assessment of a patient's illness. It requires the joint training of a medical degree and laboratory expertise to make such decisions. With respect to research and development, this cannot be seen as primarily the responsibility of the senior members of the technical profession but rather a shared one between medical staff and senior members of the medical laboratory technician staff. One would agree with the concept that all medical laboratory investigations within a district should be under a managerial head of a district laboratory, but this manager must be medically qualified. It is very divisive to suggest that the managerial head of a district laboratory should be a medical laboratory scientist, who then makes his separate approaches to a district medical management team.

The letter from Mr F S Baker and $\mathrm{Mr} \mathrm{J} \mathrm{K}$ Fawcett (5 March, p 638) does little to dispel the interpretations arising from the policy statement. How can the IMLS discuss the management of hospital laboratories without reference to medical staff? The whole issue is concerned with the joint involvement. The arguments put forward about the narrow dividing line between "technicians" and "scientists" are cogent.

As one who has considerable need for laboratory services in the management of his patients, I cannot help but feel that the whole policy document is a very divisive and counterproductive piece of information. Fortunately, I have been privileged to have always at my service a co-ordinated laboratory staff who work closely together and who, through frequent discussions, arrive at effective conclusions to meet the various needs of the patients in the hospital served. I am sure that many like me would never accept that someone without any medical training whatsoever could decide for me what tests should take priority, what tests are necessary, and when they should be done in terms of the clinical management of my patients.

In the interests of the medical laboratory services it would have been far better had the policy statement been written with due consideration of the medical staff involvement and the joint activities of all staff concerned.

H A LEE

St Mary's Hospital,

Portsmouth

\section{Allergy to diazepam and other benzodiazepines}

SIR,-I read with interest the case reports by Dr L Milner (15 January, p 144) and Dr R H Falk (29 January, p 287) describing anaphylaxis due to parenteral diazepam. I congratulate $\mathrm{Dr}$ Milner on publishing the first report on anaphylaxis due to diazepam. However, I must point out that he is erroneous in stating that hypersensitivity reactions to benzodiazepines have not been reported previously.

Between 1960 and 1975 there were at least 17 papers published documenting allergic reactions other than anaphylaxis to benzodiazepines. In most cases, chlordiazepoxide alone was the offending agent, followed by diazepam and flurazepam. In a review of cutaneous reactions to benzodiazepines Almeyda $^{1}$ reported that allergic reactions to chlordiazepoxide consisted of urticaria, angioneurotic oedema, macular erythematous rash, photoallergy, purpura with or without thrombocytopenia, erythema multiforme, erythema nodosum, and galactorrhoea. Generalised skin eruptions during chlordiazepoxide treatment, mostly by the oral route, of various neurotic and psychiatric disorders were reported by Tobin et al, ${ }^{2}$ Kinross-Wright et $a l^{3}$ Constant, ${ }^{4}$ Tobin et $a l^{5}$ and Mackie et al. ${ }^{6}$ On the other hand fixed drug eruptions due to chlordiazepoxide were noted by Gaul,? Savin, ${ }^{8}$ and Blair. ${ }^{9}$ Pruritus and purpura due to the same drug were reported by Farb ${ }^{10}$ and Copperman, ${ }^{12}$ respectively. A photoallergic reaction to chlordiazepoxide was documented by Luton et al, ${ }^{12}$ whereas Efet $^{13}$ described the occurrence of allergic keratitis during treatment with the drug. According to Rapp ${ }^{14}$ swelling of the tongue due to flurazepam developed in a patient who had apparently experienced no adverse reactions to diazepam or chlordiazepoxide.

Immediate hypersensitivity, asthmatic in character, had been associated with the intramuscular and intravenous use of diazepam, ${ }^{15}$ as also thrombocytopenic purpura $^{16}$ and conjunctivitis ${ }^{17}$ with oral diazepam. A combination of diazepam and chlor- 
diazepoxide is also reported to have caused non-urticarial reactions. ${ }^{8}$

In most cases the abnormalities resolved after the offending agent was discontinued. However, rechallenge in some instances with the aetiological agent at a later date was rapidly followed by reappearance of the allergic reactions noted earlier.

This brief review clearly establishes the fact that, although hypersensitivity reactions to diazepam and other benzodiazepines are rare, they are far from being undocumented.

JATA S GHOSH

Ardmore,

Pennsylvania

' Almeyda, J, British fournal of Dermatology, 1971, 84,

2 Tobin, J M, et al, Diseases of the Nervous System, 1960, Tobin, J M, et al, Dise

${ }^{3}$ Kinross-Wright, J, et al, Diseases of the Nervous

Kinross-Wright, J, et al, Diseases
System, 1960, 21, suppl 3, p 23.

Constant, G A, Diseases of the Nervous System, 1960 21, suppl 3, p 37

Tobin, J M, and Lewis, N D C, fournal of the American Medical Association, 1960, 174, 1242.

Mackie, B S, and Mackie, L E, Medical fournal of Australia, 1966, 2, 1034.

'Gaul, L E, Archives of Dermatology, 1961, 83, 164.

Savin, J A, British fournal of Dermatology, 1970, 83,

air, H M III, Archives of Dermatology, 1974, 109,

914

suppl 3, p 27.

Copperman, I , British Medical fournal, 1967, 4, 485. matology, 1965, 91, 362.
maton, E and Finchum,

Efet, V A, Oftal'mologicheskir Zhurnal 1973, 28, 108 . (3), Oftal' mologicheskii Zhurnal, 1973, 28, 108 1971, 105, 1020.
.

811.

Baumes, R M, Maroc Médical, 1971, 546, 321.

' Lutz, E G, American fournal of Psychiatry, 1975, 132

When is an immigrant not an immigrant?

SIR,-The interesting article by Dr K M Goel and his colleagues from Glasgow (12 March p 676) contains a common but misleading misuse of the word "immigrant." Of the "immi grant" 56 children they describe, 30 were born in the United Kingdom (which incidentally is $54 \%$, not $72 \%$ as stated). According to the Shorter Oxford English Dictionary an immigrant is "a person who migrates into a country as a settler." The parents of these children were presumably truly immigrants (as I would be if I went to live in Scotland), but the majority of the children were not. To go on calling these child citizens of the United Kingdom immigrants is not only socially unfortunate: it also conceals the fact that their medical problems may differ from those of children who have actually migrated from overseas, and did so differ in this valuable article.

Department of Paediatrics, Gepartment of Paediatrics,
London SE1

\section{Psoralens}

SIR,-In view of recent publicity which has been given to the oral use of 8-methoxypsoralen we think it is desirable that clinicians should be aware of the fact that no product licence has been granted for oral presentations either of this substance or of 2, 4, 8-trimethylpsoralen. In consequence the position is that under the Medicines Act such products cannot be legally imported into the United Kingdom except by way of special importation by or to the order of a practitioner for administration to a particular patient of his, or in accordance with a clinical trial certificate.

JOHN P GRIFFIN Principal Medical Office

Department of Health and Social

Security,

Medicines Division,

SIR,-Following the recent publicity on the treatment of psoriasis with ultraviolet light (A) and 8-methoxypsoralen many patients will be demanding this form of therapy. It is probable that local appeals will provide funds for the purchase of the equipment and it is possible that this may be given by nondermatologists. Although the treatment appears to be effective in many cases, the long-term effects in psoriasis are not known. All who use this, the so-called PUVA method, are asked to keep careful records of the patient response to measured exposure of the light and amount of drug given and to report any side effects encountered to the Committee on Safety of Medicines even though it might not be possible to show with certainty that these effects are produced by the psoralens.

H R VICKERS Consultant Adviser in Dermatology

Department of Health and
Social Security

Oxford

\section{Amoxil and Talpen}

SIR,-Dr A N P Speight (12 March, p 710), writing in support of Dr I W B Grant (12 February, p 442) states that it was impertinent of me in my reply ( $p$ 442) to question Dr Grant regarding his personal experience of amoxycillin and talampicillin. On the contrary, I would have thought it highly pertinent to inquire whether the writer has had any personal experience of the antibiotics about which he is writing. Dr Speight, however, has no such inhibitions and infers that he does not wish to be confused by the facts and states quite unashamedly that these are "minor points compared with the major issue, which is the economic one." $\mathrm{He}$ then, sir, takes up three-quarters of a column of your journal to discuss pricing, patents, and marketing, and includes for good measure reference to the advertising of cigarettes and detergents. $\mathrm{He}$ finishes with a final prod at the British National Formulary and an exhortation to the Drugs and Therapeutics Bulletin to do something about it all. I view with some suspicion the true motives of those who dwell unduly on commercial considerations, important as they are, under the cloak of academic discussion.

In contrast, Dr Grant's second letter (12 March, p 710) is worthy of serious comment as he draws attention to the comparative incidence of severe diarrhoea between ampicillin and talampicillin. ${ }^{1}$ The figures, however, that he has extracted from table 7 of my paper completely misrepresent the data, and the fallacy of the conclusion drawn from these figures would be seized upon by even an inexperienced statistician. Dr Grant's elementary error is an example of one of the classic pitfalls that all statistical students are taught to avoid in the earliest days of their training.

The true picture is that five $(1.3 \%)$ of 394 patients on talampicillin suffered from severe diarrhoea compared with eight $(2.0 \%)$ of 405 patients on ampicillin. Hence Dr Grant's conclusion that "severe diarrhoea is, if anything, more liable to occur with talampicillin than with ampicillin" is completely false. He also overlooks the other major reference $^{2}$ to a trial involving some 607 patients in which none suffered severe diarrhoea on talampicillin whereas three suffered from this symptom on ampicillin.

I feel that the public "nit-picking" of tables from papers must be extremely boring to your readers and rarely leads to any definitive conclusion. I would have hoped that $\mathrm{Dr}$ Grant would have kept his options open on amoxycillin and talampicillin, for I have no doubt that in the future he could well be applauding the virtues of these newer products.

E T KNUDSEN Medical Director,
Beecham Pharmaceuticals

Brentford, Middx ${ }^{1}$ Knudsen, E T, and Harding, J W, British fournal
of Clinical Practice, 1975, 29, 255.
2 Jaffe, G, Murphy, E J, and Robinson, O P W,
Practitioner, 1976, 216, 455.

\section{"Geriatricide"}

SIR,-I stand delightfully corrected by Professor J C Brocklehurst (19 March, p 775) and plead guilty to an etymological offence in coining the word "geriatricide" (26 February, p 555). While my meaning, of course, was clear, I would hope, at least for the present, not to see my geriatrician colleagues under threat.

I am chiefly ashamed, however, of having mixed Greek and Latin. I have received the suggestion that "senecicide" would be more correct, but I doubt my ability to rise to such pedantic heights, let alone to pronounce it in the course of an oration.

Perhaps I should have persisted in language mixing and spoken of "geronticide," but then I might have been accused of sex discrimination in ignoring the female of our species. I accept checkmate.

IAN DONALD

Glasgow

\section{Effect of intravenous disopyramide on} premature beats

SIR,-Disopyramide is an effective antiarrhythmic agent which has been available for some years as an oral preparation.

We recently administered disopyramide intravenously to 10 patients with chest pain and arrhythmias of whom eight were subsequently shown to have myocardial infarction. Seven patients had ventricular premature beats, two had ventricular tachycardia, and one had atrial tachycardia. Heart rate, blood pressure, and a rhythm strip of the electrocardiogram were taken immediately an arrhythmia was noted. The measurements were repeated after $5 \mathrm{~min}$, when a bolus injection of inert vehicle was given, followed by active disopyramide in a dose of $150 \mathrm{mg} 5 \mathrm{~min}$ later. Further measurements and blood samples were taken at 5-, 15-, and 30-min intervals after the active drug was given.

In four patients the arrhythmia ceased before the active drug was injected, in two before and in two after the vehicle. Sinus rhythm was restored at $30 \mathrm{~min}$ in all but one patient whose ventricular premature beats persisted but were less frequent. Mean levels 